\title{
BMJ Open Societal preferences for the treatment of impulsive-violent offenders: a discrete choice experiment
}

\author{
Stella Settumba (D) , ${ }^{1}$ Tony Butler, ${ }^{2}$ Peter Schofield, ${ }^{3}$ Georgina M Chambers, ${ }^{4}$ \\ Marian Shanahan (1) ${ }^{1}$
}

To cite: Settumba S, Butler T, Schofield P, et al. Societal preferences for the treatment of impulsiveviolent offenders: a discrete choice experiment. BMJ Open 2021;11:e033935. doi:10.1136/ bmjopen-2019-033935

- Prepublication history and additional online supplemental material for this paper are available online. To view these files, please visit the journal online (http://dx.doi.org/10. 1136/bmjopen-2019-033935)

Received 29 April 2020 Accepted 08 April 2021

Check for updates

(c) Author(s) (or their employer(s)) 2021. Re-use permitted under CC BY-NC. No commercial re-use. See rights and permissions. Published by BMJ.

${ }^{1}$ National Drug and Alcohol Research Centre, University of New South Wales, Sydney, NSW, Australia

${ }^{2}$ The Kirby Institute, University of New South Wales, Sydney, NSW, Australia

${ }^{3}$ School of Medicine and Public Health, The University of Newcastle, Callaghan, NSW, Australia

${ }^{4}$ National Perinatal Epidemiology and Statistics Unit, School of Women's and Children's Health, Centre for Big Data Research in Health, University of New South Wales, Sydney, NSW, Australia

Correspondence to

Dr Stella Settumba;

s.nalukwago@unsw.edu.au

\section{ABSTRACT}

Objectives The aim of this study is to quantify societal preferences for, and assess trade-offs between characteristics of treatment programmes for impulsiveviolent offenders.

Setting The study was conducted in New South Wales, Australia's largest state.

Participants The study participants were income tax payers, aged over 18 and who were able to provide informed consent.

Methods A discrete choice experiment was used to assess the preferences for treatment programmes for impulsive violent offenders. The survey presented participants with six choice sets in which they chose between two unlabelled treatment scenarios and a 'no treatment' choice. A random parameters logistic (RPL) model and a latent class (LC) model were used to analyse the societal preferences for treatment and estimate willingness to pay values based on marginal rates of substitution. Respondents were asked to self-identify if they ever had experiences with violence and subgroup analysis was done.

Results The survey was completed by 1021 highly engaged participants. The RPL model showed that society had a preference for more effective programmes, programmes that provided full as opposed to partial treatment of all co-occurring health conditions, compulsory over voluntary programmes, those with flexibility in appointments and programmes that are provided with continuity of care postprison. Respondents were willing to pay an additional annual tax contribution for all significant attributes, particularly compulsory programmes, continuity of treatment and effectiveness.

The LC model identified two classes of respondents with some differences in preferences which could be largely identified by whether they had experiences with violence or not.

Conclusion The results are important for future programme design and implementation. Programmes for impulsive violent offenders that are designed to encompass societal preferences are likely to be supported by public and tax payers.

\section{BACKGROUND}

It is estimated that 11 million people worldwide were held in penal institutions as of November 2018; a 24\% increase since

\section{Strengths and limitations of this study}

- This study goes beyond the traditional opinion polls and applies discrete choice experiment methodology to illustrate that society values treatment programmes for impulsive violent offenders.

- The study provides evidence on the specific treatment characteristics that are preferred and the benefit society derives from them expressed as willingness to pay.

- The willingness to pay values for these preferred attributes can be used in cost benefit analyses by comparing them to incremental cost per taxpayer per year incurred in the introduction or change in attribute level.

- This study includes a subgroup analysis to show the differences in preference between people who have had experiences with violence and those who have not.

- While we provide some subgroup analysis of people with experiences with violence, as a study limitation the results should be considered with caution as the experimental design focused on the societal perspective and not the various subgroups.

2000. ${ }^{1}$ In Australia, incarceration rates have increased by $98 \%$ since $2000^{1}$ despite evidence that it has little effect on reducing reoffending. ${ }^{2}$ In 2017-2018, 54\% of prisoners in Australia released from prison returned within 2 years of release. ${ }^{3}$ Alternative interventions to incarceration, especially targeted at crimes with the highest volumes of offending, could potentially have a large effect on bringing down the reoffending rate and have significant financial benefit for the public purse. $^{4}$

Violent offenders make up a significant proportion of adult offenders in Australia; in 2019 'acts intended to cause injury' accounted for almost one fifth of sentenced adults and $32 \%$ of those held on remand in New South Wales (NSW) (Australia), the state with the largest population and highest number of prisoners. ${ }^{5}$ Many violent offenders 
will reoffend when released from prison, with evidence suggesting they do so much quicker than non-violent offenders. ${ }^{6}$ Corrective Services NSW provides a nonspecific general violent offender treatment programme to inmates. ${ }^{7}$ However, a meta-analysis on treatment programmes targeting violent reoffending showed that programmes that targeted criminogenic needs (eg, substance abuse, anger, antisocial personalities, impulsivity) were more effective than those that did not. ${ }^{8}$ Pharmacotherapy-based treatment approaches for violent offenders are much less common than psychological therapies. However, among violent offenders, impulsivity has been linked to violent offending, and has been shown to correlate with altered brain serotonin functioning. This suggests that treatment with a class of drugs known as a selective serotonin reuptake inhibitor (SSRI) may regulate brain serotonin and reduce impulsivity and hence offending. ${ }^{9}$ This approach was used in a pilot study and showed improvements in behavioural measures following administration of an SSRI (sertraline). ${ }^{10}$

Effectiveness of treatment programmes for offenders, such as reducing violent crimes, is only one of many characteristics that can influence policy decisions on the provision of treatment programmes. Indeed, public perceptions of crime and their (assumed) punitive attitudes have had a large impact on incarceration rates around the world. ${ }^{1112}$ However, when the public are better engaged using deliberative methods that allow informed decision making, they provide solutions beyond punitiveness, ${ }^{13}$ including engaging in discussions on the design and delivery of treatment programmes. ${ }^{14}$ Thus, designing programmes for offenders that are characterised by societal preferential attributes may increase public support.

Discrete choice experiments (DCEs) are increasingly used in the healthcare sector to assess the strength of preferences for, and therefore, the value placed on, intervention characteristics. ${ }^{15-18}$ A DCE asks respondents to consider two or more alternative treatment choices comprised of varying characteristics (referred to as attributes) over a range of defined dimensions for each characteristic (referred to as attribute levels). By analysing respondents' trade-offs when making choices, conclusions can be made on the relative importance or preference of each characteristic. Results of such analyses can be vital to programme design, implementation and provide predictions to programme outcomes.

The aim of this research was to quantify societal preferences for, and assess trade-offs between, characteristics of treatment programmes for impulsive-violent offenders. An assessment is made on the differences in preferences between people who have had experiences with violence (offenders, victims and their families) and those without.

\section{METHODS}

This DCE is part of a wider research project, assessing societal and offender perspectives on the value of offender healthcare, with detailed methods described and published elsewhere. ${ }^{19}$ A DCE has four main stages: (1) identifying and defining attributes and levels, (2) the experimental design, (3) the data collection survey and (4) the analysis and interpretation of results. ${ }^{1820}$

\section{Identifying and defining attributes and levels}

Prior to conducting the DCE, a mixed-methods study was undertaken to identify and define attributes and relevant levels. The methods and results of this study were detailed in a previously published article. ${ }^{14}$ This process included seven focus group discussions (FGDs) with offenders and members of the general population, one in-depth interview with a family member of an offender, within group prioritising methods of voting and ranking, and a Delphi method with 13 experts in the justice sector to select a list of eight final attributes to be used in the experimental design of the DCE (summarised in table 1).

\section{Experimental design}

The experimental design for the survey was generated using NGENE software. ${ }^{21}$ An unlabelled design with three alternatives was chosen; that is, treatment 1 , treatment 2 and no treatment. A no treatment option was included because the research intended to evaluate the trade-offs between attributes and not necessarily a choice between treatments. ${ }^{22}$ A dual-response design was adopted where respondents were forced to choose between treatment 1 and 2 in a follow on question if they chose the "no treatment' option. With eight attributes, four of which had five levels each and two with three levels each, a full factorial design of $5625\left(5^{4} \times 3^{2}\right)$ possible choice tasks was not feasible for respondents to complete. Thus, following recommended practice, a statistically reduced partial factorial experimental design to estimate main effects was obtained. ${ }^{20}$

This design sought to achieve both statistical and response efficiency, that is, one that would achieve statistical significance with small standard errors yet engage respondents in such a way that none of the attributes were ignored in choice making. A D-efficient Bayesian experimental design ${ }^{23}$ generated 24 choice scenarios which were blocked into 4 sets of 6 choice tasks each. A D-efficient design seeks to minimise the determinant of the asymptotic variance covariance matrix of models estimated on the data collected which in turn minimises the standard errors, making it possible to obtain more reliable parameter estimates. ${ }^{24}$ Effects coding was used for categorical variables. To aid the effects coding ranking of the levels for categorical variables was explored during the qualitative study. For example, during these FGDs participants for example preferred programmes provided in prison only (without follow-up post prison) to those provided in community only (without continuity when offenders are imprisoned or leave programmes).

Two pilot studies to pretest the questionnaire were undertaken. In the first pilot, a basic multinomial logistic (MNL) design was obtained with very small near-zero initial priors. This was administered to 100 participants. 
Table 1 Summary of attributes and their levels used in the experimental design

\begin{tabular}{l} 
Attribute \\
\hline Effectiveness of the \\
treatment among \\
programme participants.
\end{tabular}

Location and continuity of treatment.

\section{Attribute levels}

$10 \%, 30 \%, 50 \%, 70 \%$ of care post prison);
Prison only (with no continuity community only (with no continuity of care when imprisoned); prison with continuity of care post prison; Both prison and community with continuity of care in between transitions.

$\begin{array}{ll}\begin{array}{l}\text { Treatment of co-occurring } \\ \text { health conditions/addictions. }\end{array} & \begin{array}{l}\text { Minimal treatment provided } \\ \text { in programme; full treatment } \\ \text { of all co-occurring health } \\ \text { conditions/addictions both } \\ \text { within programme and at } \\ \text { referral facilities. }\end{array} \\ \text { Type of treatment } & \text { Offender group counselling } \\ \text { programme. } & \text { sessions only; offender } \\ & \text { wroup counselling sessions } \\ & \text { counselling with medication; } \\ & \text { individual and family } \\ \text { counselling with medication. } & \text { Health professionals; prison/ } \\ \text { probation and parole officers } \\ \text { wreatment providers. } \\ \text { prison/probation and parole } \\ \text { officer with counsellors/ } \\ \text { psychologists with health } \\ \text { professional; counsellors/ } \\ \text { psychologists with health } \\ \text { professional. }\end{array}$

Flexibility of appointments. Not flexible, flexible.

Compulsory/ Voluntary Compulsory, voluntary.
participation.

Cost per tax payer per year. \$A25, \$A50, \$A75, \$A100

Reprinted with permission from Settumba et al. ${ }^{14}$

The prior coefficient sign used for the cost attribute was assumed negative with all the others assumed positive. The parameter estimates from this pilot provided Bayesian priors to be used in the second pilot with each variable assumed to have a normal distribution. The second design was an MNL model evaluated against both a mixed and a latent class (LC) model. The S-efficient measure in NGENE was then used to determine a sample size of 830 participants required for a statistically significant estimate of each parameter. ${ }^{2124}$

Qualitative data from the first pilot study indicated that a large percentage of respondents primarily considered, as key, two attributes when making their choice; cost and effectiveness of the treatment programme. While this did not suggest that the other attributes were not important, it indicated that taxpayers appeared concerned about the value of their taxes in terms of the effectiveness of the programme. Good choice tasks are those that result in trade-offs between the attributes and do not have strongly dominant alternatives. Thus, in the second pilot study, constraints were placed in the design to ensure that in some choice tasks both cost and effectiveness were equal over the two alternatives. This provided an opportunity to analyse the trade-offs between other attributes.

\section{Data collection survey}

Choice sets obtained from the experimental design were used to design the questionnaire. Societal perspectives were obtained online from a general population recruited by a commercial online panel provider (Survey Sampling International (SSI) ) in June 2018. Email invitations were sent to NSW panel members only. The sample was selected to be representative of the NSW taxpayer population in terms of age, sex and geographical location (rural or metropolitan areas). Respondents were all NSW income tax-paying residents, over 18 years of age, who provided consent to participate in the study. A taxpayer in Australia is an individual who earns above the base taxable threshold income (\$A18 200 a year) and therefore pays through annual tax returns a percentage of their income as tax. Treatment for offenders is more likely to be funded through tax payers' government funding and therefore it was important that the values and preferences used were for tax payers. Each respondent was randomly allocated to one of four questionnaire blocks and tasked with six choice sets. An assumption was made that if the sample population was demographically similar to the general tax payer population, their behavioural pattern in terms of choice between treatments would be similar.

Along with demographic characteristics, respondents were asked about their experience with violence by indicating if they had ever been accused of perpetrating violence, subjected to violence, family member of someone accused of perpetrating violence, family member of someone subjected to violence, or if they had no experience of violence. Violence was described to all participants as follows:

According to $\mathrm{WHO}$, violence is the intentional use of physical force or power, threatened or actual, against oneself, another person or against a group or community, which either results in or has a high likelihood of resulting in injury, death, psychological harm, maldevelopment or deprivation. Prior to the choice tasks, respondents were provided with definitions and information on violence and impulsivity, rates of violence in NSW, and information on treatment programmes available for violent offenders. They were also provided with summarised definitions as well as links to detailed explanations of the attributes used in the DCE.

Respondents were tasked to choose between treatment 1, treatment 2 and no treatment options using the following question: 
Which treatment would you prefer to be given to impulsive violent offenders?

Respondents who chose the 'no treatment' option were presented with a follow-up forced task asking them to choose between treatment 1 and treatment 2 (forced choice) using the following question:

If you had to choose between treatment 1 and treatment 2, which one would you prefer?

To assess participant engagement in the study the length of time it took participants to complete the survey questionnaire was also recorded. Respondents were also asked to state which attributes they ignored when making choices and to indicate how easy or difficult it was to answer the choice task. The survey also had a qualitative follow-up question asking respondents to comment on the survey.

\section{Data analyses}

The demographic characteristics of the participants were compared with those of the NSW population. The number of participants that chose the 'no treatment' alternative for each choice task was examined to make a decision on whether to include it in the analysis or use the forced choice.

DCEs analyses are rooted in two economic theories, McFadden's ${ }^{25}$ and Lancaste's ${ }^{26}$ framework based on the random utility theory. Estimations are based on the assumption that if participants chose a treatment it was because it gave them a higher utility as a result of the level of the attributes in that treatment. As shown in equation 1 , the utility $(U)$ that an individual $n$ derives from the treatment alternative $j$ in the choice set $c$ is explained by an observed component $V_{n c i}$ and an unobserved component $\varepsilon_{n c j}$.

$$
U_{n c j}=V_{n c j}+\varepsilon_{n j}
$$

(equation 1)

The observed component of the utility associated with alternative $\mathrm{j}, V_{n c}$, is a function of a vector of $\mathrm{K}$ attributes that describe treatment alternative $t, x_{n c k}$, with associated preference weights, $\beta$, to be estimated. Such that:

$$
\mathrm{V}_{\mathrm{ncj}}=\sum_{\mathrm{k}=1}^{\mathrm{K}} \beta_{\mathrm{k}} \mathbf{x}_{\mathrm{ncjk}}
$$

(equation 2)

Analyses were conducted in NLOGIT using logistic models. A basic MNL model was estimated to ensure functionality. This was followed by a random parameters logit (RPL), a fixed parameters LC logit (LCL) model and a random parameters LC (RPLC) model.

Unlike the MNL model, in the RPL model the independent of irrelevant alternative property is relaxed by allowing heterogeneity in respondent preference. The LCL model assumes that preferences are discretely distributed and are similar among individuals within clusters/classes but vary between clusters. ${ }^{27}$ Model improvement for both the RPL and RPLC models was tested using the log-likelihood function and the Akaike Information Criterion (AIC) in comparison with the MNL and LCL models, respectively.
In this study, based on the attributes described in table 1, the model description based on equation 2 can be explained as:

$$
\begin{aligned}
& U_{\text {treatment }}=\beta_{\text {constant }}+\beta_{\text {effectiveness }}+\beta_{\text {location and continuity of treatment }}+ \\
& \beta_{\text {treatment of co-occurring health conditions/addictions }}+\beta_{\text {type of treatment }}+ \\
& \beta_{\text {treatment provider }}+\beta_{\text {flexibility of appointments }}+ \\
& \beta_{\text {compulsory or voluntary participation }}+\beta_{\text {cost }}
\end{aligned}
$$

Choice probabilities in RPL models take on a multidimensional integral which is estimated using simulation. The RPL models were estimated using 500 random Halton draws, which have been proved to produce better estimations than random draws. ${ }^{28}$ An initial attributes-only RPL model was estimated with all $\beta$ parameters treated as random parameters. Ultimately, a parameter was denoted as random (ie, unobserved heterogeneity in preference for a specific attribute) when the modelling process indicated a statistically significant parameter mean and SD around the estimated parameter mean. Model complexity was reduced based on the log-likelihood ratio test against the attributes-only model while retaining significant predictors of choice $(\mathrm{p}<0.05)$. Only the parameters 'effectiveness of the treatment', 'cost' and 'compulsory/voluntary participation' were treated as random parameters. All other parameters that were not statistically significant when treated as random and were treated as fixed parameters. All parameters were treated as having a normal distribution. This was because various models were developed with different distributional assumptions and the normal distribution proved superior based on goodness of fit statistics.

The model was then fitted with covariates: respondent characteristics and interaction terms. Various respondent characteristics, that is, experience with violence, age, sex, residential location, income and education, were tested but only 'experience with violence' was significant and improved the model based on the log-likelihood ratio test. Interaction terms of interest were then tested. The parameter 'effectiveness of the treatment programme' was interacted with all other parameters, one interaction at a time, but none were significant. The random parameters were also interacted with respondent characteristics of 'age' and 'experience with violence'.

Using the respondents' answers to the question regarding their experience with violence, sub-groups were constructed and RPL models were estimated for each group. For the sub-group of people with no experiences with violence, the variable denoting people who had an objection to the treatment of violent offenders was interacted with the variables 'flexibility of appointments', 'compulsory/voluntary programmes' and 'effectiveness of the treatment programme'. This was of interest because a larger percentage of people who objected to the treatment of offenders were those who had no experiences with violence (98\% of $\mathrm{N}=672$ ). A parametersonly RPL model was fitted for all other subgroups, that 
is, offenders, family members of offenders, victims and family members of victims.

A fixed parameters LC model was followed by a RPLC model. After determining the number of classes based on model fit, model convergence and significance, respondent variables were added as covariates to describe the class compositions. The random parameters were 'effectiveness of the treatment' and 'compulsory/voluntary participation'.

Estimation of willingness to pay (WTP) values (and their SD) were based on conditional estimates from the RPL model in the WTP space, which take into account individual heterogeneity as a result of random attributes and specifies the distribution of WTP directly at the estimation stage rather than the standard approach of specifying the distributions of the coefficients and deriving WTP as the ratio of two coefficients (estimation in preference space). For more details on a RPL model in the WTP space we refer the reader to an article by Rose and Masiero. ${ }^{29}$ The WTP for a binary or categorical attribute is the incremental tax participants are WTP to have the attribute or characteristic relative to the base as part of the treatment programme for impulsive violent offenders. The WTP for a continuous attribute is the incremental tax for every unit increase in the attribute that participants are willing to pay. The calculation, which in effect quantifies the trade-offs that society would be willing to make, is a simulated-based estimate described as the marginal rates of substitution between a statistically significant attribute parameter of interest and the cost parameter, weighted by the loglikelihood function. ${ }^{30}$

DCEs are based on the fundamental premise that individuals are rational when making choice (ie, consider all available information and make decisions on the basis of maximising their utility) and are willing to trade between choices. To assess this rationality in choice, participant study engagement was analysed by considering the percentage of participants that responded to optional qualitative questions and the time taken to complete the questionnaire. In addition, the number of participants who always chose the same treatment (either treatment 1, 2 or none), that is, straightlining for each choice set was calculated. While straightlining may not necessarily be irrational it is an indication of not attending to tasks.

Participants were also tasked to indicate, by checking as many boxes from a list of provided attributes, which attributes they paid least attention to when making choice.

\section{Patient and public involvement}

This DCE demonstrates the involvement of both offenders and the general public in making decisions about the treatment of offenders. Both offenders and the general public were involved in developing DCE attributes and attribute levels through qualitative research. The DCE sample includes members of the general public. A future DCE with offenders is planned.

\section{RESULTS}

\section{Participant characteristics}

In total, 1021 participants completed the questionnaire with a $100 \%$ response rate for all six choice tasks per participant thus generating 6126 observations. Time to complete the questionnaire ranged from 3 to $76 \mathrm{~min}$ with a median time of completion of 9 min. Demographic characteristics of the sample participants are summarised in table 2. Our study sample was similar to that of the NSW taxpayer population in terms of age, sex and residential location and respondents' characteristics were similar across the four questionnaire blocks. Taxpayers' household income and education level data were not obtainable from the Australian taxation office.

\section{Participant study engagement}

The number of respondents that provided responses to the optional general qualitative comments about the study was $82 \%$ indicating an extremely high level of engagement in the study question.

Overall, $54 \%$ of respondents stated that they paid equal attention to all attributes when making choice. The percentage of respondents who stated having paid least attention to an attribute were: $8.2 \%$ for 'treatment of co-occurring health conditions/addiction', $8.6 \%$ for 'compulsory/voluntary participation', $9.0 \%$ for 'effectiveness of the treatment', $11.3 \%$ for 'location and continuity of care', $12.4 \%$ for 'type of treatment', $14.2 \%$ for 'cost', $16.4 \%$ for treatment provider' and $18.1 \%$ for 'flexibility of appointments'.

No respondents chose the same treatment (either treatment 1, 2 or 'no treatment') for all choice sets. For each choice set, the percentage of respondents who preferred the 'no treatment' option was very low (between 1.3\% and $3.5 \%$ ), and therefore, the choice modelling was focused on the forced choice that is, between treatment 1 and treatment 2

\section{Results from the random parameter logit model}

Table 3 provides the results of the RPL model, which we highlight as the key result model for this study (for robustness all other models are available as appendices). The RPL model is preferred to the MNL model (online supplemental appendix 1) (log-likelihood function of -3714.93 compared with -3962.92). While the signs of all the significant coefficients remained the same in the move to the RPL model, the coefficient for the attribute level 'prison/probation and parole officers with health professionals' as a treatment provider becomes insignificant.

The significant coefficients of the RPL model indicate that holding other variables constant, when choosing a treatment programme for impulsive violent offenders, participants preferred more effective treatments, treatment programmes that cost less per tax payer per year, and programmes that provide full provision of treatment 
Table 2 Sample characteristics compared with the NSW taxpayer population $(N=1021)$

\begin{tabular}{|c|c|c|c|c|c|c|}
\hline & \multirow{3}{*}{$\begin{array}{l}\text { NSW taxpayer } \\
\text { population* } \\
(\%)\end{array}$} & \multirow{3}{*}{$\begin{array}{l}\text { Study } \\
\text { sample } \\
(\%)\end{array}$} & \multicolumn{4}{|c|}{ Questionnaire block } \\
\hline & & & 1 & 2 & 3 & 4 \\
\hline & & & (\%) & & & \\
\hline \multicolumn{7}{|l|}{ Gender } \\
\hline Females & 48 & 49 & 50 & 51 & 49 & 48 \\
\hline Males & 52 & 51 & 50 & 49 & 51 & 52 \\
\hline \multicolumn{7}{|l|}{ Age } \\
\hline $18-24$ & 10 & 11 & 11 & 11 & 12 & 10 \\
\hline $25-34$ & 21 & 19 & 20 & 18 & 18 & 20 \\
\hline $35-44$ & 22 & 21 & 22 & 18 & 20 & 21 \\
\hline $45-54$ & 21 & 19 & 18 & 22 & 19 & 20 \\
\hline $55-64$ & 16 & 17 & 16 & 17 & 18 & 17 \\
\hline $65+$ & 10 & 12 & 13 & 14 & 13 & 12 \\
\hline \multicolumn{7}{|l|}{ Residential location } \\
\hline Metro & 71 & 68 & 68 & 69 & 67 & 70 \\
\hline Rural & 29 & 32 & 32 & 31 & 33 & 30 \\
\hline \multicolumn{7}{|l|}{ Annual household Income } \\
\hline$<25 K$ & - & 3 & 2 & 3 & 3 & 3 \\
\hline $25 \mathrm{~K}-50 \mathrm{~K}$ & - & 15 & 14 & 14 & 17 & 16 \\
\hline $51 \mathrm{~K}-100 \mathrm{~K}$ & - & 30 & 31 & 26 & 32 & 31 \\
\hline $101 \mathrm{~K}-150 \mathrm{~K}$ & - & 23 & 23 & 26 & 21 & 23 \\
\hline$>150 \mathrm{~K}$ & - & 16 & 18 & 17 & 16 & 12 \\
\hline Prefer not to say & - & 13 & 12 & 14 & 11 & 15 \\
\hline \multicolumn{7}{|l|}{ Education } \\
\hline Did not complete secondary school & - & 6 & 5 & 6 & 6 & 6 \\
\hline Graduated from secondary school & - & 16 & 16 & 15 & 19 & 17 \\
\hline TAFE and Trade qualification & - & 32 & 31 & 31 & 34 & 32 \\
\hline University qualification & - & 46 & 48 & 48 & 41 & 45 \\
\hline Not stated & - & - & - & - & - & - \\
\hline
\end{tabular}

*According to the 2016-2017 Australian Taxation Office statistics NSW, New South Wales.

of all co-occurring health conditions both within the programme and at referral (compared with minimal treatment provided within the programme). There was also a preference for compulsory over voluntary participatory programmes and programmes that have flexibility in appointments over those that do not.

For the attribute 'location and continuity of treatment', when compared with 'both prison and community with continuity of care in between transitions', 'prison with continuity of care' is preferred. Respondents expressed a disutility for programmes provided either in community or prison alone with no continuity of care when imprisoned or postprison. Treatment provision by counsellors or psychologists alongside health professionals was preferred over health professionals alone.

Analysis of interaction terms indicated that people who had experience with violence preferred programmes with voluntary rather than compulsory participation. Also, compulsory participation became more preferred as respondents' age increased.

The WTP results (interpreted as additional annual tax for a unit increase in the continuous variable and for a categorical or binary variable level relative to its base) shows that holding all other attributes constant in the RPL model, the marginal rate of substitution of significant attributes to the cost attribute revealed that respondents were willing to pay an additional annual tax contribution over and above what they currently pay (in 2018 AUD) of:

- $\$ \mathrm{~A} 2.40(\mathrm{SD}=\$ \mathrm{AA} 0.90)$ for every $1 \%$ increase in effectiveness of treatment programmes.

- \$A27.30 ( $\mathrm{SD}=\$ \mathrm{~A} 4.20)$ to have programmes provided in both prison and community with follow-up in between transitions compared with programmes in prison only without follow-up postprison. 
Table 3 Results from the random parameters logit model

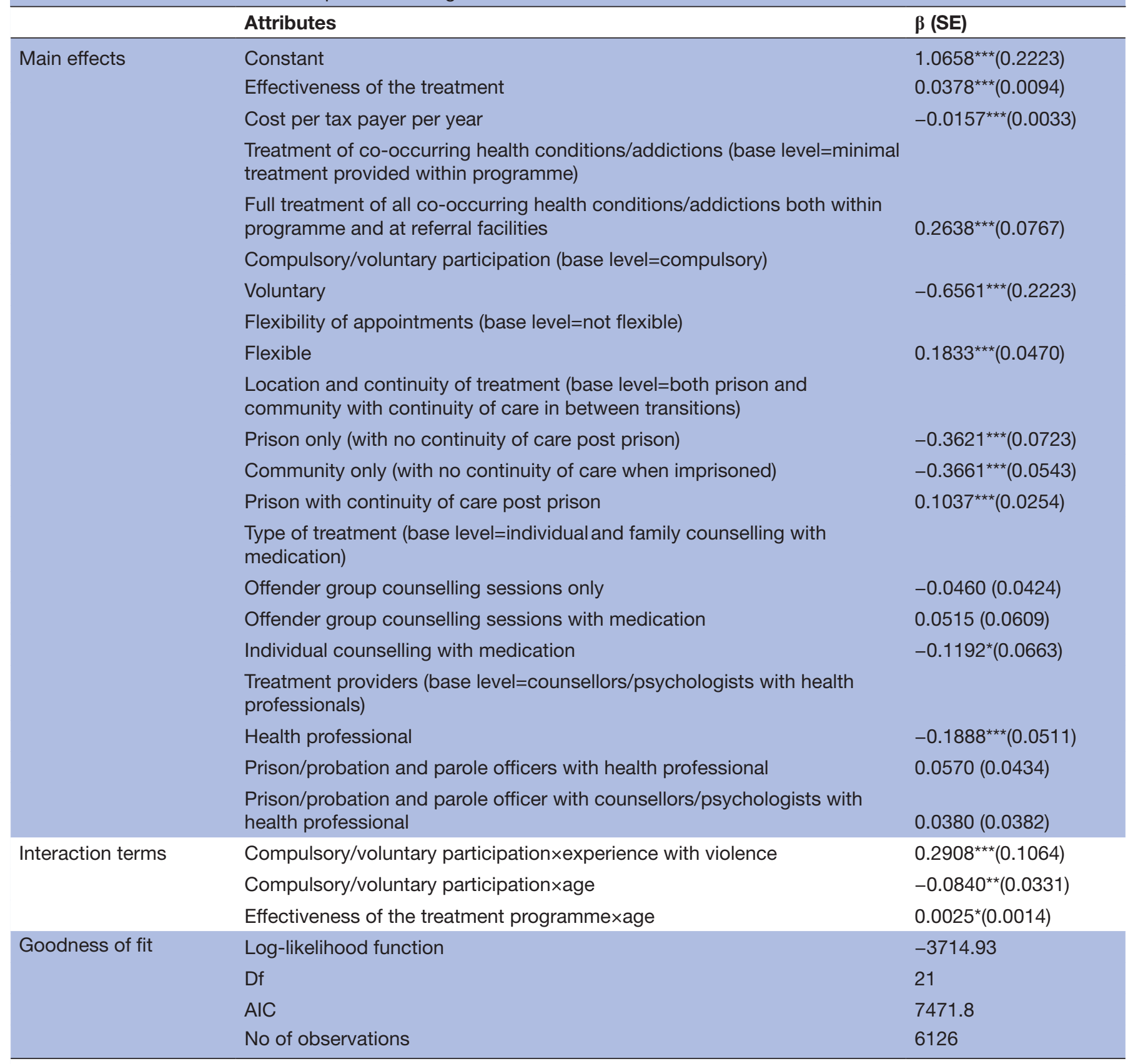

*** $99 \%$ confidence level, ${ }^{* *} 95 \%$ confidence level, * $90 \%$ confidence level.

AIC, Akaike Information Criterion.

- $\$ \mathrm{~A} 27.20(\mathrm{SD}=\$ \mathrm{~A} 4.20)$ to have programmes provided in both prison and community with follow-up in between transitions compared with programmes in community only without follow-up when imprisoned.

- $\$ \mathrm{~A} 7.70(\mathrm{SD}=\$ \mathrm{~A} 2.50)$ to have programmes provided in prison with follow-up postprison compared with having them provided in both prison and community with follow-up in between transitions

- \$A19.80 $(\mathrm{SD}=\$ \mathrm{A6} .40)$ to have programmes that provide full treatment of all coexisting health conditions/addictions both in the programme and at referral facilities compared with programmes that provide minimal treatment within the programme.

- $\$ \mathrm{~A} 13.90(\mathrm{SD}=\$ \mathrm{~A} 3.00)$ to have programmes provided by both health workers and counsellors or psychologists compared with health professionals only.

- \$A14.00 ( $\mathrm{SD}=\$ \mathrm{~A} 3.00)$ to have programmes that have flexibility in appointments compared with those that are not flexible.

- \$A37.00 ( $\mathrm{SD}=\$ \mathrm{~A} 8.20)$ to have programmes that have compulsory participation of impulsive violent offenders than those with voluntary participation. 


\section{Results}

Results for the LC models are reported in online supplemental appendix 2. A move from the LC to the LCRPL did not improve the model (ie, the log-likelihood function changed from -3723.66 to -3727.92 ) and all the coefficients maintained the same sign and size. Therefore, the LC model was compared with the RPL model. Compared with the RPL model, the LC did not improve the model (log-likelihood function of -3714.93 and -3727.92). The RPL was, therefore, used as the final model. However, the LC model has some interesting results that can be used to explain the sample participants. The best LC model fit has two classes. The class probabilities, that is, the chance that participants will belong to a class, are $60 \%$ in class 1 and $40 \%$ in class 2 . The class membership shows that class 1 is more likely to have those who had experiences with violence than class 2 (a coefficient of 0.4033 at $95 \%$ confidence level).

Key differences are class 2 members preferred programmes that are flexible over those that are not flexible while class 1 appears to be indifferent (coefficient not significant). Class 2 also preferred programmes that are located in prison with continuity of care post-prison in comparison to those provided in both prison and community with continuity of care in between transitions while the coefficient for this attribute is insignificant for class 1 . Compared with class 2 , which had an insignificant coefficient, class 1 members preferred individual counselling with medication over individual and family counselling with medication as a treatment type. Compared with counsellors or psychologists with health professionals as treatment providers, class 1 preferred prison or probation and parole officers with health professionals while this attribute's coefficient was insignificant for class 2.

\section{Subgroup analysis}

While the experimental design was not designed for subgroup analyses it is clear that there are response differences in groups based on participants' experiences of violence, therefore, we further explored these groups. Here, we present results for MNL and RPL models for the subgroups: offenders $(n=31)$, victims $(n=217)$, family members of offenders $(n=59)$, family members of victims $(\mathrm{n}=192)$ and people with no reported violence experience $(n=672)$ in online supplemental appendix 3. Of note, participants were not equally distributed across questionnaire blocks and this was especially true for the offender group. All RPL models for each group improved compared with the MNL models. The main differences in the RPL models are presented below.

Similar to the LC model, people with no reported experience with violence preferred programmes with flexible appointments compared with those that are not flexible. The coefficient for flexibility of appointments was insignificant for other groups. Offenders, victims and people with no experience with violence preferred programmes provided in prison with continuity of care post-prison compared with those provided in both prison and community with continuity of care in between transitions. This was not significant for family members of either offenders or victims. Compared with counsellors or psychologist with health professionals as treatment providers, offenders prefer health professionals with prison or probation and parole officers.

\section{CONCLUSION}

The aim of this study was to quantify societal preferences for, and assess trade-offs between, characteristics of treatment programmes for impulsive-violent offenders. Using a DCE, results suggest that society prefers programmes that are effective, are provided in prison with follow-up post prison, provide full treatment of all co-occurring health conditions/addictions, provide flexible appointments, are provided by health workers together with prison or probation and parole officers and have compulsory participation. It is interesting to note that society prefers and are WTP more for programmes that have a follow-up component than those without. However they prefer programmes provided in prison with follow-up over those provided in both community and prison with follow-up between transitions. This suggests that society finds better value for money for programmes that are prison based with follow-up.

The LC model showed that differences exist between subgroups of the society. In this study, the subgroups were based on participant experiences with violence. This provides some further explanation on heterogeneity between groups that might result in preferential differences when it comes to making choice for treatment programmes for impulsive violent offenders.

Treatment of offenders is a controversial topic with opinion polls often revealing a largely punitive society that is in favour of incarceration and harsher prison sentences. ${ }^{11}$ This is especially true for crimes such as violence which society perceives as being more serious than others. ${ }^{31}$ However, evidence suggests that opinion polls are often misleading. With advances in research methodologies designed to accurately determine public opinion, and when presented with facts about the limited effectiveness of incarceration and the associated staggering costs, there is an increasing understanding of the public's attitude to crime ${ }^{32}$ and an appetite for rehabilitation. ${ }^{33}$ Results from DCE's such as the one described here provide evidence that societal support for treatment programmes can be better explained when consideration is made of the characteristics (attributes) of the treatment programmes.

As in many other DCEs in the health area, this study shows that society is likely to support treatment programmes for impulsive violent offenders if they are effective. ${ }^{34-36}$ Consistent with economic theory, the negative coefficient for the attribute 'cost per tax-payer per year' suggests there is a preference to pay less rather than more. 
Our study demonstrates that society has a preference for treatment programmes that are compulsory as opposed to voluntary for violent offenders and that taxpayers are willing to pay an additional annual tax of $\$$ A37 to have programmes made compulsory. Compulsory programmes for offenders are often contentious. A systematic review of the effectiveness of compulsory illicit drug and alcohol treatments reported that the percentage of studies that found negative impacts on criminal recidivism when comparing compulsory and voluntary treatment was similar to the percentage that observed positive impacts. ${ }^{37}$ However, this may be due to drug dependence having a different mechanism to violence. In a qualitative study conducted prior to this DCE study, ${ }^{14}$ results showed that while the general public was split between compulsory versus voluntary programmes, offenders preferred voluntary programmes. While offenders thought they would more likely benefit from a programme where they were allowed to opt-in, FGD participants with the general public thought of violent offending as a serious crime needing programmes to be compulsory. ${ }^{14}$ This is reflected in the results of the interaction terms in the RPL model that indicate that participants that had experiences with violence preferred voluntary programmes.

There is a consensus among researchers that violence should be considered to be a public health problem and not confined to the criminal justice area. ${ }^{38}$ Public health models to tackle violence are being advocated globally and emphasis is placed on prevention rather than reacting once an offence has been committed. ${ }^{39} 40$ Programmes like REINVESt, a public health intervention that seeks to treat impulsive violent offenders with a pharmacotherapy, have shown effectiveness in a pilot study and a randomised controlled trial is currently underway to further investigate its effectiveness. ${ }^{10}$ The programme is voluntary and is provided by nurses and psychologists in the community to men with a history of at least two violent offences. Participants are referred by local court magistrates or probation and parole officers. The programme provides some flexibility for the men to make monthly follow-up appointments, where they receive their medications and are routinely monitored. The results of the RPL suggest that a programme such as REINVESt is likely to have societal support should it prove to be effective in reducing reoffending. Support is also apparent because the programme is delivered by psychologists alongside nurses and offers flexible appointments. Additional societal endorsement would arise from it being made compulsory (currently it is voluntary), and delivered in prison with postprison continuity rather than only in the community.

The study pilot suggested that both cost and effectiveness attributes were key in the treatment choice. While this did not suggest that other attributes were not important it may suggest that respondents see other attributes as contributing to the effectiveness of the programme. Interaction terms between effectiveness and all other attributes were included in the design but not found significant. This may be as a result of the constraints placed in the design over the cost and effectiveness attributes. One suggestion could be to conduct a DCE without the effectiveness attribute but this would have made the treatment alternative descriptions lacking as effectiveness of any offender programme is a key characteristic. The results suggest that participants majority of participants did not ignore any attributes when making choice. However, it should be noted that this was a selfreported evaluation.

The value of programmes to offenders should also be assessed. Qualitative research prior to this DCE showed that offenders and the public consider similar attributes when making choices but there was difference between groups over the levels of the attributes. ${ }^{14}$ While we provide some subgroup analysis of people with experiences with violence, as a study limitation the results should be considered with caution as the experimental design focused on the societal perspective and not the various subgroups. As a recommendation for future work, DCEs should be performed to assess preferences of the various subgroups of people that have experienced violence, especially offenders. This would be essential if programmes are designed to not only increase public support but offender uptake as well.

A recent systematic review found a lack of economic evidence to support programmes in the criminal justice space. ${ }^{41}$ In addition to influencing policy on the design of offender programmes, the findings of this study can be used in cost-benefit analyses of treatment programmes for impulsive violent offenders. Using REINVESt as an example, if the programme was made compulsory for all impulsive violent offenders, the additional cost incurred per tax-payer per year would be compared with the additional benefit (WTP for compulsory over voluntary programmes) of $\$ A 37$ per tax payer per year. If the difference in the dollar amount was greater than 0 , then a policy that required compulsory treatment of impulsive violent offenders would be considered to have a net monetary benefit and thus be considered good value for money.

The study had some limitations. This study included only income tax payers as participants. While this was a feasible way of obtaining preferences and WTP through voluntary tax increments, it excluded many potential participants who contribute to tax in various other ways. We would like to recognise that people who do not pay income tax are still legitimate stakeholders in public policy whose views should not have been excluded. The results therefore can be generalised to the NSW tax-payer population but may not be representative of the entire population.

The study design and analysis included cost and effectiveness as continuous variables. This suggests that WTP estimates from such models assume a constant marginal utility of income which may not be true among participants. A suggestion would be to evaluate these attributes as categorical. While this would have made the preference 
task and evaluation easier, it would undermine the validity of WTP.

It should also be noted, just like in many stated preference study, that the 'warm glow' effect exists that is, the potential for participants to choose a WTP value that they would not be willing to pay in real situations. A study using the contingent valuation for the same sample has been conducted and is currently being analysed. Results from this DCE will be validated with those from the contingent valuation study.

In conclusion, this DCE offers an assessment of preferences for treatment programmes for impulsive violent offenders that should be used to inform the design of programmes. Society values treatment programmes especially if they effective, are provided in prison with follow-up postprison, provide full treatment of all co-occurring health conditions/addictions, provide flexible appointments, are provided by health workers together with prison or probation and parole officers and have compulsory participation.

Acknowledgements We acknowledge all participants for this study's pilot and main survey.

Contributors SS, MS, GC, PWS and TB were involved in the study concept and design. SS and MS were involved in the data analysis. All authors contributed majorly to the data interpretation and write up of the manuscript.

Funding This study was funded by grants from the National Health and Medical Research Council, under the Centre of Research Excellence in Offender Health Australia (grant number RG124596). It is part of the research done by the Justice and Health programme, Kirby Institute.

Competing interests None declared.

Patient consent for publication Not required.

Ethics approval The study received ethics approval from the University of New South Wales Human Research Ethics Committee (HC17848). All procedures performed in studies involving human participants were in accordance with the ethical standards of the institutional and/or national research committee and with the 1964 Helsinki declaration and its later amendments or comparable ethical standards.

Provenance and peer review Not commissioned; externally peer reviewed.

Data availability statement Data are available on reasonable request. The data from this study are available from the corresponding author on request. This will involve approvals from ethics and completion of a data sharing agreement. The data include deidentified participant data and an analysis plan.

Supplemental material This content has been supplied by the author(s). It has not been vetted by BMJ Publishing Group Limited (BMJ) and may not have been peer-reviewed. Any opinions or recommendations discussed are solely those of the author(s) and are not endorsed by BMJ. BMJ disclaims all liability and responsibility arising from any reliance placed on the content. Where the content includes any translated material, BMJ does not warrant the accuracy and reliability of the translations (including but not limited to local regulations, clinical guidelines, terminology, drug names and drug dosages), and is not responsible for any error and/or omissions arising from translation and adaptation or otherwise.

Open access This is an open access article distributed in accordance with the Creative Commons Attribution Non Commercial (CC BY-NC 4.0) license, which permits others to distribute, remix, adapt, build upon this work non-commercially, and license their derivative works on different terms, provided the original work is properly cited, appropriate credit is given, any changes made indicated, and the use is non-commercial. See: http://creativecommons.org/licenses/by-nc/4.0/.

ORCID iDs

Stella Settumba http://orcid.org/0000-0001-8514-7770

Marian Shanahan http://orcid.org/0000-0001-9873-3576
REFERENCES

1 Walmsley R. World prison population list. Institute for Criminal Policy Research (ICPR), 2018.

2 Weatherburn D. The effect of prison on adult re-offending. BOCSAR NSW Crime and Justice Bulletins, 2010: 12.

3 Australian Government Productivity Commission. Report on government services 2016. Canberra, Australia, 2016.

4 Lowenkamp CT, Latessa EJ. Understanding the risk principle: how and why correctional interventions can harm low-risk offenders. Topics in community corrections 2004;2004:3-8.

5 NSW Bureau of Crime Statistics and Research. New South Wales Custody Statistics Quarterly Update March 2019, 2019.

6 Jones Cet al. Risk of re-offending among parolees. BOCSAR NSW Crime and Justice Bulletins, 2006: 12.

7 Ware J, Cieplucha C, Matsuo D. The Violent Offenders Therapeutic Programme (VOTP)-Rationale and effectiveness, 2011.

8 Dowden C, Andrews DA. Effective correctional treatment and violent reoffending: a meta-analysis. Canadian Journal of Criminology 2000;42:449-67.

9 da Cunha-Bang S, Hjordt LV, Perfalk E, et al. Serotonin 1B receptor binding is associated with trait anger and level of psychopathy in violent offenders. Biol Psychiatry 2017;82:267-74.

10 Butler T, Schofield PW, Greenberg D, et al. Reducing impulsivity in repeat violent offenders: an open label trial of a selective serotonin reuptake inhibitor. Aust N Z J Psychiatry 2010;44:1137-43.

11 Enns PK. The Public's Increasing Punitiveness and Its Influence on Mass Incarceration in the United States. Am J Pol Sci 2014;58:857-72.

12 Van Kesteren J. Public attitudes and sentencing policies across the world. Eur J Crim Pol Res 2009;15:25-46.

13 Hutton N. Beyond populist punitiveness? Punishm Soc 2005;7:243-58.

14 Settumba SN, Shanahan M, Butler T, et al. Developing attributes and choice experiment: an example for interventions of impulsive violent offenders. Appl Health Econ Health Policy 2019;17:683-705.

15 de Bekker-Grob EW, Ryan M, Gerard K. Discrete choice experiments in health economics: a review of the literature. Health Econ 2012;21:145-72.

16 Ryan M, Gerard K. Using discrete choice experiments to value health care programmes: current practice and future research reflections. Appl Health Econ Health Policy 2003;2:55-64.

17 Clark MD, Determann D, Petrou S, et al. Discrete choice experiments in health economics: a review of the literature. Pharmacoeconomics 2014;32:883-902.

18 Lancsar E, Louviere J. Conducting discrete choice experiments to inform healthcare decision making: a user's guide. Pharmacoeconomics 2008;26:661-77.

19 Settumba SN, Shanahan M, Chambers GM, et al. Assessing societal and offender perspectives on the value of offender healthcare: a stated preference research protocol. BMJ Open 2019;9:e024899.

20 Reed Johnson F, Lancsar E, Marshall D, et al. Constructing experimental designs for discrete-choice experiments: report of the ISPOR conjoint analysis experimental design good research practices Task force. Value Health 2013;16:3-13.

21 Choice metrics. NGENE 1.1.2 user manual and reference guide, 2014.

22 de Bekker-Grob EW, Hol L, Donkers B, et al. Labeled versus unlabeled discrete choice experiments in health economics: an application to colorectal cancer screening. Value Health 2010;13:315-23.

23 Kessels Ret al. Recommendations on the use of Bayesian optimal designs for choice experiments. Qual Reliab Eng Int 2008;24:737-44.

24 Rose JM, Bliemer MCJ, Hensher DA, et al. Designing efficient stated choice experiments in the presence of reference alternatives. Transportation Research Part B: Methodological 2008;42:395-406.

25 McFadden D. Conditional logit analysis of qualitative choice behavior Berkeley, CA: University of California, 1973.

26 Lancaster KJ. A new approach to consumer theory. J Polit Econ 1966;74:132-57.

27 Greene WH, Hensher DA. A latent class model for discrete choice analysis: contrasts with mixed logit. Transportation Research Part B: Methodological 2003;37:681-98.

28 Train K. Halton sequences for mixed logit. Berkeley, CA: University of California, 2000.

29 Rose JM, Masiero L. A comparison of the impacts of aspects of prospect theory on WTP/WTAEstimated in preference and WTP/WTA space. European Journal of Transport and Infrastructure Research 2010;10.

30 Greene WH, Hensher DA, Rose JM. Using classical simulationbased estimators to estimate individual WTP values, in applications 
of simulation methods in environmental and resource economics. Springer, 2005: 17-33.

31 Warr M. Public perceptions and reactions to violent offending and victimization. Understanding and Preventing Violence 1994;4:1-66.

32 Frost NA. Beyond Public Opinion Polls: Punitive Public Sentiment \& Criminal Justice Policy. Sociol Compass 2010;4:156-68.

33 Simpson PLet al. Assessing the Public's Views on Prison and Prison Alternatives: Findings from Public Deliberation Research in Three Australian Cities. Journal of Public Deliberation 2015;11:1.

34 Glenngård $\mathrm{AH}$, Hjelmgren J, Thomsen $\mathrm{PH}$, et al. Patient preferences and willingness-to-pay for ADHD treatment with stimulants using discrete choice experiment (DCE) in Sweden, Denmark and Norway. Nord J Psychiatry 2013;67:351-9.

35 Essers BAB, Arits AH, Hendriks MR, et al. Patient preferences for the attributes of a noninvasive treatment for superficial basal cell carcinoma: a discrete choice experiment. Br J Dermatol 2018;178:e26-7.
36 Guimarães C, Marra CA, Gill S, et al. A discrete choice experiment evaluation of patients' preferences for different risk, benefit, and delivery attributes of insulin therapy for diabetes management. Patient Prefer Adherence 2010:4:433

37 Werb D, Kamarulzaman A, Meacham MC, et al. The effectiveness of compulsory drug treatment: a systematic review. Int J Drug Policy 2016;28:1-9.

38 Krug EG, Mercy JA, Dahlberg LL, et al. The world report on violence and health. The Lancet 2002;360:1083-8.

39 Rutherford A, Zwi AB, Grove NJ, et al. Violence: a priority for public health? (Part 2). J Epidemiol Community Health 2007;61:764-70.

40 Moore MH. Public health and criminal justice approaches to prevention. Crime Justice 1995;19:237-62.

41 Settumba SNet al. Are we getting value for money from behavioral interventions for offenders? A research note reviewing the economic evaluation literature. American Journal of Criminal Justice 2017. 